\title{
EnERGyTEST: A Tool for Assessing Building Energy Sustainability
}

\author{
Emilio Ancillotti*, Raffaele Bruno*, Emanuele Crisostomi ${ }^{\dagger}$, Mauro Tucci ${ }^{\dagger}$, Marco Conti* \\ *Inst. of Informatics and Telematics, Italian National Research Council (CNR) \\ email: $\{$ e.ancillotti,r.bruno,m.conti\}@iit.cnr.it \\ $\dagger$ Department of Energy, Systems, Territory and Constructions Engineering, University of Pisa, Italy \\ email: \{e.crisostomi, m.tucci\}@unipi.it
}

\begin{abstract}
There is a growing interest in the development of (nearly) zero-energy buildings (ZEBs), i.e., buildings that deliver (nearly) the same amount of energy to the supply grid as it is drawn from it on a yearly basis. This paper investigates the ability of such ZEBs to performing in a truly self-sustainable fashion, i.e., minimising the frequency of energy exchange with the outer grid, through appropriate charging/discharging actions of a storage system. A realistic simulation environment called ENERGYTEST is developed on purpose to simulate the electrical load consumption in an aggregate of houses, in order to perform the sustainability assessment.
\end{abstract}

Index Terms-zero energy building (ZEB), electrical loads, PV, energy storage, building energy use, energy model, simulation.

\section{INTRODUCTION}

The increasing penetration level of energy produced from renewable sources has been one of the main drivers in the recent design of so-called demand side management (DSM) techniques. The fluctuating and non-programmable nature of renewable energy makes it simpler and more desirable for the smart grid to shift the electric domestic loads, when possible, to the periods of power generation. While the effects of DSM actions might not be relevant at the level of a single house, as not so many loads can be shifted in time without causing inconvenience to the people in the house, the advantages become more considerable at an aggregated level. In this perspective, many authors in the related literature have proposed aggregated strategies to implement peak-shaving actions [1] and [2], to coordinate energy generation and consumption [3], to aggregate prosumers (i.e., people that consume energy and at the same time generate power via small PhotoVoltaic (PV) or wind plants) [4].

The energy management of individual buildings, or clusters of buildings, is becoming a particularly attractive topic of interest, in view of recent regulations, see for instance the directives 2002/91/EC and 2010/31/EU from the European Union $^{1}$, which aim at improving the energy performance of buildings within the Union. In particular, such directives require all member states to guarantee by the end of 2020 that all new buildings are nearly zero-energy buildings (and 2018 for new buildings occupied and owned by public authorities). The notation of (nearly) zero-energy buildings (ZEBs) refers to the ability of the buildings to deliver (nearly) the same amount of energy to the supply grid as it is drawn from it on a yearly basis.

\footnotetext{
${ }^{1}$ http://ec.europa.eu/energy/efficiency/buildings/buildings_en.htm
}

Recent results related to the optimal management of ZEBs, either at a home or at a neighbourhood level can be found in [5] and [6].

One drawback of the philosophy underlying ZEB management is that not always the grid will be able to accommodate the (small) energy produced by ZEBs due to a variety of reasons usually related to grid management and stability (e.g., the grid network is already working near the power constraints, or it could be too expensive or too complicated from a control perspective to handle small flows of powers in the Buildingto-Grid direction). For such reasons, it is highly desirable from the grid perspective that the ZEBs should be able to work in an isolated manner as much as possible, and reduce the energy exchange with the grid, especially in the direction from the building to the grid. In this view, the objective of this paper is to simulate the energy management of an aggregate of houses (e.g., a building or an entire neighbourhood), and to show how much self-sustainable it is in practice. We make the assessment of sustainability as a function of the energy produced by the aggregate of houses (e.g., as a function of the size of available PV panels on the roofs), and of the capacity of a battery that can be used to store locally produced energy, when this exceeds the local energy demand. Then, the stored energy is given back to the building when needed without requiring the same energy from the grid. Obviously, the more energy is produced by the building, and the larger is the capacity of the battery to store energy, the more sustainable is the building. Overall, the contribution of this paper is two-fold: $i$ ) the assessment of actual self-sustainability of an aggregate of houses as a function of self-generated energy and battery capacity, and (ii) the implementation of a realistic simulator, called ENERGYTEST, to evaluate the stochastic fluctuations of domestic electrical loads in a whole year. Note that throughout the paper, for the sake of simplicity, we limit our discussion to the management of the only electrical energy.

This paper is organised as follows. Section II illustrates in greater detail our simulation tool, including the description of the neighbourhood scenario, the modelling of the electrical loads, the PV model, the battery model and the software architecture. Section III summarises and discusses the results obtained after a whole year simulation of the described scenario. Finally, Section IV concludes the paper and outlines current line of research of the authors. 


\section{Building ENERgy Simulation ToOl}

In this section we describe all the models that have been used by our building energy simulation tool ENERGYTEST to simulate the electrical energy generation and consumption in an aggregate of buildings. Also, we briefly describe the software architecture of the simulation environment.

\section{A. Smart Building Model}

Figure 1 schematically exemplifies our building energy simulation tool. An individual housing unit is the basic element

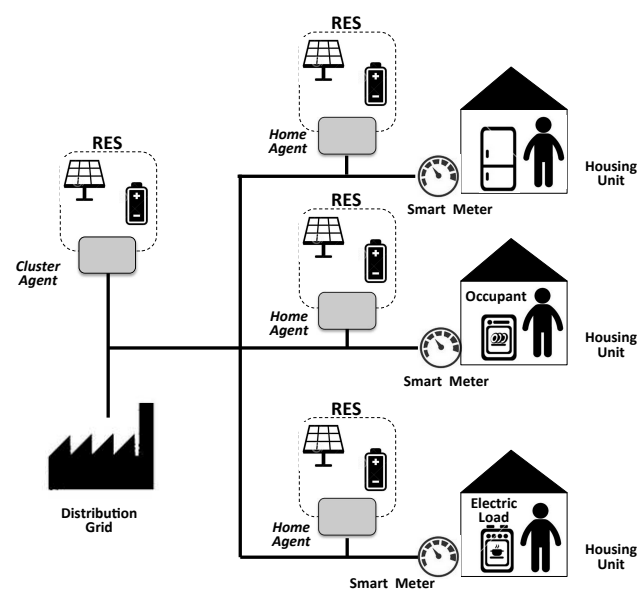

Fig. 1. Smart building model

of the smart building model: it includes both the electrical loads and the house occupants who interact with the domestic appliances. A housing unit may use self-generated energy (e.g., from PV panels), energy bought from the outer power grid, or both. In addition, we assume that a smart meter is deployed at each housing unit to monitor the energy consumption and to transmit this information to other parties. Note that a housing unit can range from a single flat in a building to a singlefamily detached house. Thus, the same model can be applied to an apartment building, a complex of several buildings, up to a whole neighbourhood.

We assume that an individual housing unit can also own an energy storage system. In turn, this provides some extra flexibility to the house energy management system, that we will denote as home agent from now on, to improve the sustainability of the housing unit. For instance, the home agent may decide under which conditions and criteria the energy produced by the PV panel should be used to recharge the energy storage or to satisfy the energy demands of the electric appliances in the housing unit. Note that the PVs can be associated with a single flat in a building or to the entire building. In the second case, we will have an aggregate agent that is responsible for sharing the available energy between the housing units that are part of the same aggregate. Also a hybrid solution is available if some renewable energy resources (RESs) are owned by single houses (e.g., PV panels), and some other RESs are shared among all the houses/buildings in the neighbourhood, e.g., a wind plant. Finally, we assume that all housing units are also connected to a low voltage power grid.

\section{B. Electrical Loads}

A housing unit usually contains a large variety of electrical loads. For simplicity, we group household electrical loads into two broad categories: background loads and interactive loads. The first class of electrical loads is typically driven by automatic controllers (e.g., thermostats or timers) and house occupants set target objectives (e.g., a desired temperature) but they are not concerned with the power demand patterns of the appliance (i.e., when it is on or how much power is consumed). Typical examples of background loads are heaters and air conditioners. The second class of electric loads are directly controlled by house occupants who manually turn them on and off. Interactive loads include a diverse collection of appliances, such as cooking equipments (e.g., microwaves, kettles, cookers), washing machines, home entertainment devices (e.g., TVs) and lighting. In the following, we describe the physical and stochastic models that we have used to simulate the power consumption of some of the most common (and energy-hungry) household appliances: air conditioners (ar), heat pumps ( $h p$ ), fridge $(f r)$, freezer $(f z)$, water heater $(w t)$, dishwasher $(d w)$, washing machine (wm), cooking (co) and lighting (lt).

1) Background Loads: We focus on background loads that are controlled by a thermostat because the energy consumption can be easily expressed though a mathematical equation that relates the internal temperature of the appliance at time $t$, say $\theta(t)$, with the physical characteristics of the environment (ambient temperature), appliance attributes (thermal insulation, efficiency), house occupants' activities, appliance status (on or off state), users' preferences and demanded comfort levels [7]-[9]. More formally, let $\theta_{o}$ be the thermostat set-point, while $\theta_{\max }$ and $\theta_{\min }$ are the upper and lower temperature limits for the set-point $\theta_{o}$. Typically, $\theta_{\max }=\theta_{o}+\theta_{b} / 2$, and $\theta_{\text {min }}=\theta_{o}-\theta_{b} / 2$, where $\theta_{b}$ is known as the thermostat deadband. Thus, a thermostatically controlled appliance should maintain its internal temperature within the range specified by the user to meet his expectations (e.g., a comfortable room temperature, frozen food, hot water). This goal can be expressed through the following set of mathematical equations:

$$
\begin{gathered}
s\left(t_{n}\right)= \begin{cases}-1 & \text { if } \theta_{\min } \leq \theta\left(t_{n}\right) \leq \theta_{\max }\{\mathrm{ac}, \mathrm{fr}, \mathrm{fz}\} \\
1 & \text { if } \theta_{\min } \leq \theta\left(t_{n}\right) \leq \theta_{\max }\{\mathrm{wh}, \mathrm{hp}\} \\
0 & \text { otherwise. }\end{cases} \\
\theta\left(t_{n+1}\right)=\beta \theta\left(t_{n}\right)+(1-\beta)\left[T_{a}+\eta \frac{s\left(t_{n}\right) P}{A}\right]+\Phi\left(t_{n}\right),
\end{gathered}
$$

where $s\left(t_{n}\right)$ is the status (on or off) of the appliance at timestep $t_{n}, \gamma$ is the time-step duration (i.e., $\gamma=t_{n+1}-t_{n}$ ), $A$ is the thermal conductivity (units of $\mathrm{Wh} /{ }^{\circ} \mathrm{C}$ ), $m_{c}$ is the thermal mass $\left({ }^{\circ} \mathrm{C} / \mathrm{W}\right), \beta$ is the appliance's energy efficiency: $\beta=\exp \left(-\gamma A / m_{c}\right)$ [7], $T_{a}$ is the ambient temperature, $P$ is the constant power consumed by the appliance to cool down/heat up its thermal mass (units of W), and $\Phi\left(t_{n}\right)$ is a noise process used to introduce stochastic thermal fluctuations due to house occupants' behaviours. We now further explain function $\Phi\left(t_{n}\right)$ for the single household appliances modelled in ENERGYTEST, while in Section III-A we list the specific values of the model parameters for each appliance. For the sake 
of simplicity we assume that the process $\Phi\left(t_{n}\right)$ depends only on the house occupancy level, i.e., the number of house occupants at time $t_{n}$. The occupancy model that we have implemented in ENERGYTEST is a stochastic model that defines the schedule of indoor/outdoors activities based on the role of each home occupant (e.g., worker or non-worker). Then, individual activity patterns are aggregated into a home-level activity profile. This approach has the advantage to easily accommodate for different sizes and types of households. A detailed description of the procedure to calculate the house occupancy level and all input data can be found in [2].

a) Air conditioner/heat pump: The number of house occupants affects the indoor air temperature [9], as well as the number of air changes per room [10]. Without loss of generality, we model all these phenomena by assuming that each occupant causes a random increase (decrease in case of heat pumps) of the ambient temperature by $0.5^{\circ} \mathrm{C}$ for every hour he/she spends in the house.

b) Refrigerator/Freezer: Intuitively the internal temperature of a refrigerator and freezer is affected by the opening of the appliances [11]. For simplicity we assume that an opening event causes an increase of $\theta(t)$ by $0.5^{\circ} \mathrm{C}$, and that each occupant generates on average one opening every two hours.

c) Electrical water heater: The energy consumption of water heaters varies with the usage profiles of hot water, which depend in turn on the habits of home occupants. For the sake of simplicity we only consider large water draw events, which cause the temperature of the water in the tank to decrease down to $\theta_{\min }$ [12]. Then, we assume that each home occupant randomly generates one large water draw event per day.

2) Interactive Loads: The energy demand profile of interactive loads may depend in a complex and unpredictable manner on the household habits and the house occupancy. Hence, it might be difficult to provide physical models of the energy demands of interactive loads based on the stochastic occurrence of a diverse set of miscellaneous events. For these reasons the energy consumption of interactive loads is commonly modelled through stochastic models that characterise the average load curves. Such stochastic models are typically derived from historical data on energy consumption of different appliances [9] and from survey data describing what people do and when [13], [14]. Specifically, in ENERGYTEST we have considered two classes of interactive electrical loads. One group is denoted as cycle-based loads because it is characterised by well-defined operation cycles (i.e., dishwashers and washing machines). A second group is denoted as variable loads because their operations are not constrained by a cycle (i.e., cooking and lighting).

In the case of cycle-based loads we assume that there is a single operation cycle per day with a given probability $\tau_{i}, i \in \mathrm{wm}, \mathrm{dw}$. Then, let us assume that each day can be partitioned into $m$ time periods of equal duration (e.g., for hourly load curves the time period is one hour and $m=24$ ). The following tuple of random variables is utilised to model the energy consumption of an operation cycle:

$$
\left(T_{i}^{o n}, E_{i}^{o n}, D_{i}^{o n}\right), \quad i \in\{\mathrm{wm}, \mathrm{dw}\}
$$

where $T_{i}^{o n}$ is the index of the time period when the appliance is used, $E_{i}^{o n}$ is the energy (Wh) consumed during the entire operation cycle, and $D_{i}^{o n}$ is the duration (in time steps) of the operation cycle. For simplicity we assume that the power consumption is constant during the entire cycle. For instance, the tuple $(9 \mathrm{AM}, 800 \mathrm{Wh}, 2 \mathrm{~h})$ indicates that the appliance is turned on at $9 \mathrm{AM}$, the operation cycle consumes $800 \mathrm{Wh}$ and the cycle duration is two hours, which correspond to a power consumption of $400 \mathrm{~W}$. Clearly, $T_{i}^{o n}, E_{i}^{o n}$ and $D_{i}^{o n}$ are random variables that follow arbitrary distributions. We rely on the results shown in [14] to empirically derive those distributions in the case of washing machines and dishwashers, as better explained in Section III-A.

In the case of variable loads we adopt a slightly different stochastic model for the energy consumption. Specifically, we associate with each time-period $k$ of a day the following tuple of variables

$$
\left(R_{i}^{k}, P_{i}^{k}\right), \quad i \in\{\mathrm{co}, \mathrm{lt}\},
$$

where $R_{i}^{k}$ is the probability that the appliance $i$ is used in the time period $k$, and $P_{i}^{k}$ is the average power (W) consumed by the appliance in the time period $k$. The rationale behind this modelling approach is that it facilitates the characterisation of appliances that are typically used many times during the day. Again, we rely on the results shown in [14] to empirically derive the distributions of $R_{i}^{k}$ and $P_{i}^{k}$. Note that such distributions vary over the months of the year (e.g., lights are used differently in summer and winter seasons), and we included seasonality effects in our model accordingly.

\section{Solar Photovoltaics (PV) Panels}

The power generated from the PV panels can be computed as

$$
P\left(t_{n}\right)=a \cdot G\left(t_{n}\right)+b \cdot G\left(t_{n}\right) \cdot T_{a}\left(t_{n}\right)+c \cdot G(k)^{2},
$$

where at a given time step $t_{n}, T_{a}\left(t_{n}\right)$ is the outdoor temperature $\left({ }^{\circ} \mathrm{C}\right), G\left(t_{n}\right)$ is the irradiance (in $W / m^{2}$ ), and $a, b$ and $c$ are constructive parameters that take into account the technology, the shape and the size of the PV panels. Specifically, we have used $a=22.92, b=-0.1140$ and $c=-0.0030$, and we have scaled the power output as a function of the desired size of the PV panels. More details of the model underlying equation (4) can be found, for instance, in reference [15]. To obtain realistic values of the output power of the PV panel we have used temperature and irradiance data collected by a meteorological station in the town of Pisa (Italy). over a period of one year.

\section{Energy Storage}

We consider here a simple model for the battery. We assume that the battery is either charged or discharged with a constant power within every time step (1 second in our simulations). Accordingly, its state of charge (SOC) varies as specified by the following equations

$$
\begin{aligned}
& \operatorname{SOC}\left(t_{n}\right)=S O C\left(t_{n-1}\right)+P_{b} \cdot \Delta T / C_{b} \\
& \text { subject to }\left\{\begin{array}{l}
\frac{P_{b}}{S O C_{b} \leq \overline{P_{b}}} \leq S O C\left(t_{n}\right) \leq S O C_{\max } \\
S O C_{\text {min }}
\end{array}\right.
\end{aligned}
$$

where $P_{b}$ is the power delivered (positive) or taken (negative) from the battery in an interval of time $\Delta T, C_{b}$ is the capacity 
of the battery and the SOC is expressed as a fraction of the overall capacity. The two constraints in (5) refer to the fact that the charge/discharge power is limited, and that the SOC can not exceed $S O C_{\max }$ (e.g., the capacity), and can not be smaller than a minimum level of energy $S O C_{\min }$ to avoid endangering the lifetime of the battery. In our simulations, we fixed the maximum discharge power to $150 \mathrm{~kW}$, the maximum charge power equal to $50 \mathrm{~kW}$ and studied the same scenario for different capacities of the battery. Also, we assumed that there were some charge-discharge losses equal to $5 \%$. The model and the data are consistent with, for instance, [16].

\section{E. Software Design}

ENERGYTEST is a discrete event simulator that is built using $\mathrm{C}++$ and perl. The core of the simulator is written in $\mathrm{C}++$ by taking advantage of the Adevs library ${ }^{2}$. This $\mathrm{C}++$ library supports the construction of discrete event models using the Parallel DEVS formalism, which is designed to facilitate the description of discrete event systems through simple state transition tables [17]. Specifically, an atomic DEVS model is defined by specifying: $i$ ) the set of input events, $i i$ ) the set of output events, $i i i)$ the set of sequential states, $i v$ ) the time advance function, which determines the lifespan of a state, $v$ ) the external transition function, which defines how an input event changes a state of the system, vi) the internal transition function, which defines how a state of the system changes when the elapsed time reaches to the lifetime; and vii) the output function, which defines how a state of the system generates an output event when the elapsed time reaches to the lifetime of the state. Then, we have developed DEVS-based objects for modelling the behaviour of the following entities: Home Occupant, Housing Unit, Appliance, PV, Battery, Agent, Meter, Power Grid, as well as the interactions between them. Finally, the perl scripting language is used to set the simulation scenario.

\section{Evaluation}

We have used our simulator ENERGYTEST to assess the impact of energy storage and PV installed capacity on the selfsustainability of a building. To this end we have simulated a building composed of ten housing units which are served by a centralised PV panel and an energy storage (see Figure 1). The building agent operates as follows:

- if the energy supplied by the PV panel is greater than the energy demand from household appliances, then the energy surplus is used to charge the battery;

- if the battery is fully charged the energy in excess is passed to the grid or, if not possible, is "discarded". In practice, the discarded energy could be employed in a useful manner (e.g., to heat the water in a boiling unit), but such features have not been modelled here;

- if the energy demand from household appliances is greater than the energy supplied by the PV panel, the energy storage is first used to compensate for the supply-demand mismatch and if not enough, the residual energy is drawn from the grid.

Then we try to address the following issues: $i$ ) What should be the "optimal" capacity of the PV panel and of the energy

${ }^{2}$ http://web.ornl.gov/ 1qn/adevs/
TABLE I

PARAMETER SETTINGS FOR BACKGROUND LOADS.

\begin{tabular}{|l|c|c|c|c|}
\hline & air cond/heat pump & refrigerator & freezer & water heater \\
\hline$\theta_{o}$ & $22-23^{\circ} \mathrm{C} / 19-20^{\circ} \mathrm{C}$ & $5^{\circ} \mathrm{C}$ & $-24^{\circ} \mathrm{C}$ & $(55 \pm 3)^{\circ} \mathrm{C}$ \\
\hline$\theta_{b}$ & $1{ }^{\circ} \mathrm{C}$ & $4{ }^{\circ} \mathrm{C}$ & $4{ }^{\circ} \mathrm{C}$ & $3{ }^{\circ} \mathrm{C}$ \\
\hline$A$ & $(62.5 \pm 12.5) \mathrm{Wh} /{ }^{\circ} \mathrm{C}$ & $3.21 \mathrm{Wh} /{ }^{\circ} \mathrm{C}$ & $1.06 \mathrm{Wh} /{ }^{\circ} \mathrm{C}$ & $13.6 \mathrm{Wh} /{ }^{\circ}$ \\
\hline$m_{c}$ & $1{ }^{\circ} \mathrm{C} / \mathrm{kW}$ & $(20 \pm 4)^{\circ} \mathrm{C} / \mathrm{W}$ & $(13.65 \pm 2)^{\circ} \mathrm{C} / \mathrm{W}$ & $(4.28 \pm 1)^{\circ} \mathrm{C} / \mathrm{W}$ \\
\hline$\eta$ & 2.5 & 3 & 1.95 & 2 \\
\hline$\gamma$ & $1 \mathrm{sec}$ & $1 \mathrm{sec}$ & $1 \mathrm{sec}$ & $1 \mathrm{sec}$ \\
\hline$P$ & $1.5 \mathrm{KW}$ & $120 \mathrm{~W}$ & $150 \mathrm{~W}$ & $300 \mathrm{~W}$ \\
\hline
\end{tabular}

storage system to provide a zero-energy building? ii) How much energy produced by the PV panel has to be fed back to the grid or discarded? and iii) How do these behaviours change when the thermostat set points are modified?

In the following tests each housing unit has two air conditioners/heat pumps. The maximum number of house occupants in each household is randomly selected in the range $[2,4]$. The house occupancy patterns are generated as described in [2]. The complete list of parameter values for the energy consumption model of each appliances is provided in the following section. The statistical significance of the results is obtained through ten independent replications of each test. Note that a test corresponds to the simulation of the energy consumption in the whole building for a period of one year.

\section{A. Input Data}

In order to simulate the building energy performance, it is important to select appropriate model parameters which are close to those in the real world. There are several studies that have determined physical-based load models of thermostatically controlled appliances though appliance performance tests [9]. Similarly, a number of investigations of the thermal properties of buildings are available in the literature [?]. In this study the parameter settings for background loads in Equation (1b) are taken from [8], [9], [18], [19]. Furthermore, we have made the assumption that each air conditioner (heat pump) is used for cooling (heating) an area of $25 \mathrm{~m}^{2}$, while a capacity of 50 litres is considered for the water heaters. For the sake of clarity, all input data for the background loads are listed in Table I. The parameters relative to the interactive loads have been extracted from [14], a comprehensive survey of electrical power demand and energy consumption in 251 households in England over the period May 2010 to July 2011. Specifically, Figure 2(a) and Figure 2(b) show the hourly usage pattern and distribution of per-cycle energy consumption of dishwashers and washing machines. The cycle duration $D^{\text {on }}$ for a dishwasher and $D^{\text {on }}$ for a washing machine are modelled as follows:

$$
D_{d w}^{o n}=\left\{\begin{array}{ll}
30 m & \text { if } E_{d w}^{o n} \in[100: 600] \\
1 h & \text { if } E_{d w}^{o n} \in[700: 1000] \\
1.5 h & \text { if } E_{d w}^{o n} \in[1100: 1300] \\
2.0 h & \text { if } E_{d w}^{o n} \in[1400: 1700] \\
2.5 h & \text { if } E_{d w}^{o n} \in[1800: 2100] \\
3 h & \text { if } E_{d w}^{o n} \in[2200: 2300]
\end{array}, \quad D_{w m}^{o n}= \begin{cases}30 m & \text { if } E_{w m}^{o n} \in[100: 200] \\
40 m & \text { if } E_{w m}^{o n} \in[300: 400] \\
1 h & \text { if } E_{w m}^{o n} \in[500: 800] \\
1.5 h & \text { if } E_{w m}^{o n} \in[900: 1300]\end{cases}\right.
$$




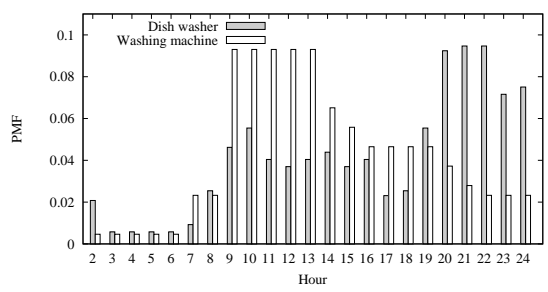

(a) $T_{i}^{o n}$ distribution

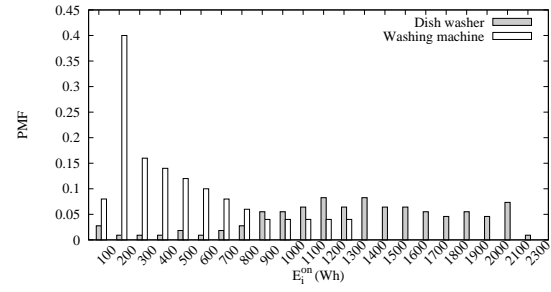

(b) $E_{i}^{o n}$ distribution

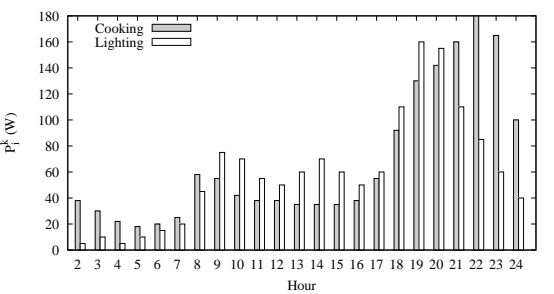

(c) Daily average load curve for variable loads

Fig. 2. Input data for interactive loads

Figure 2(c) shows the hourly average power consumption for cooking and lighting, which are two non-cycled loads. For the sake of realism, a seasonal factor is applied to power consumption of lighting. More specifically, power consumptions are increased in the winter season by a factor 1.7, while in the summer season are decreased by a factor 0.5 . Please note that the load curves of lighting and cooking implicitly accounts for the fact that the use of such appliances is more frequent in specific periods of the day. Therefore, we can assume that $R_{i}^{k}$ in Equation (3) is only needed to introduce a noise process in the load curve. Finally, we used real outdoor temperature, humidity and solar irradiance levels for our simulations, corresponding to 1-year data collected from meteorological datasets of the town of Pisa (Italy).

\section{B. Results}

Figure 3 shows the fraction of the total energy demand of the building that is supplied by the PV, the energy storage system and the power grid respectively, for different values of installed PV capacities and battery capacities. The 2 diagrams in Figure 3 correspond to different temperature set points for air conditioners and heat pumps. The interesting aspect arising from our simulations, is that the ZEB is not truly self-sufficient in the sense that even assuming that the PV can provide a power equal to $90 \mathrm{~kW}$, only about $40 \%$ of the consumed energy is actually supplied by the PV cells. The situation improves rapidly by introducing a local energy storage that can compensate for the mismatches between renewable energy production and energy demands. Specifically, an electricity storage with capacity of $30 \mathrm{kWh}$ reduces the amount of energy supplied by the grid over one year from $60 \%$ to $40 \%$. This reduction increase of a further $15 \%$ if a larger storage system with capacity up to $240 \mathrm{kWh}$ is installed. Interestingly, it can be seen by comparing the results in Figure 3(b) and Figure 3(a) that if home occupants are willing to accept a small discomfort by varying the temperature set points of air conditioners and heat pumps by one degree (from $20^{\circ} \mathrm{C}$ to $19^{\circ} \mathrm{C}$ in the winter and from $22^{\circ} \mathrm{C}$ to $23^{\circ} \mathrm{C}$ in the summer), the building selfsustainability improves only by a small fraction. To gather a more detailed insight of the system dynamics, Figure 4 shows the energy produced by the PV panel while Figure 5 shows the energy load and the profiles of the battery SOC over a period of 5 days in the first week of June for the same parameter settings used in Figure 3(a). First of all, Figure 4 shows that

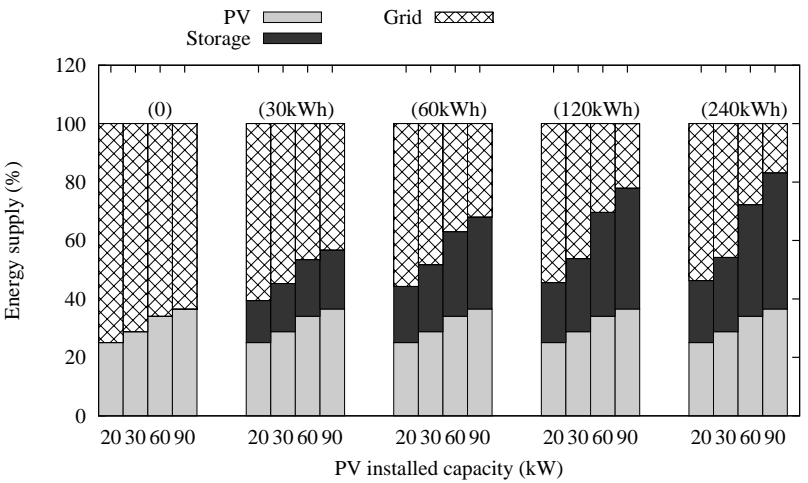

(a) Temperature set points: $22^{\circ} \mathrm{C}$ (summer), $20^{\circ} \mathrm{C}$ (winter)

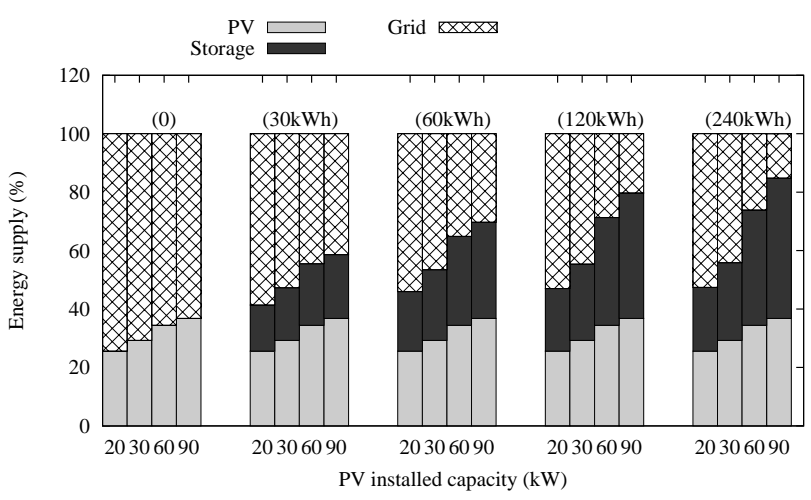

(b) Temperature set points: $23^{\circ} \mathrm{C}$ (summer), $19^{\circ} \mathrm{C}$ (winter)

Fig. 3. Fraction of energy demands that are supplied by the PV panel, the energy storage and the power grid

the power generated by the PV panel is a bell-shaped curve with random distortions due to solar irradiance variabilities caused by atmospheric conditions. This is an expected result, as the solar power density over a period of one day is also a bellshaped curve. Figure 5(a) depicts the energy load profile of the entire building (in $\mathrm{kW}$ consumed per minute). The comparison of the mismatch between the power demand and the solar power supply is very useful to explain the state of charge of the battery. Indeed, Figure 5(b) shows that the battery is typically fully charged during the morning, when the PV panel produces an 


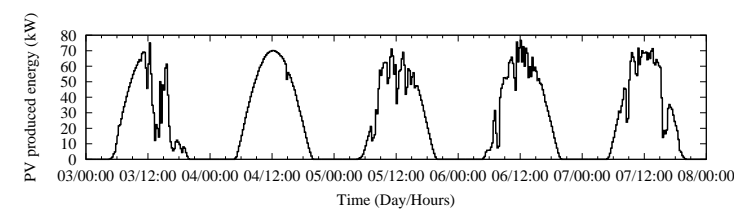

Fig. 4. Energy produced by the PV panel.
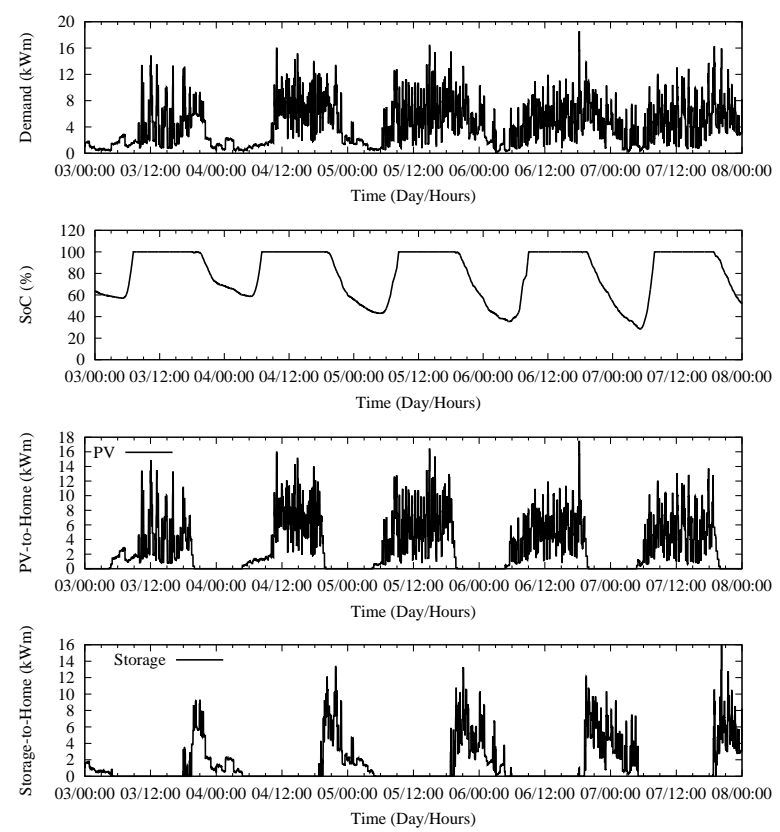

Fig. 5. Energy profiles over a period of 5 days in the first week of June. From top to the bottom, it is shown the energy load profile, the battery stateof-charge, the energy supplied by the PV panel and the energy supplied by the storage to the building

energy surplus with respect to the overall energy demand of the building. Then, the battery gets discharged in the evening (see Figure 5(d)) when the energy produced by the PV panel is smaller than the required load. During the day, when the storage is already fully charged, the PV panel must feed back its energy surplus to the power grid. Thus, we can conclude that the zeroenergy conditions do correspond to self-sustainability only if a significant investment in storage capacity is undertaken.

\section{CONCLUSIONS}

The definition of ZEBs usually involves the balancing of the generated and consumed energy in a building. However, if the power is generated and consumed at different times of the day, this might imply that the buildings are far from being truly self-sustainable, as they continuously have to buy and sell energy from the outer grid. This feature is not simply handled by current power grids, especially as the number of buildings participating to the energy exchange programme is increasing. In this paper, we developed a realistic electrical load simulator to quantify the mismatch between the generated and consumed electrical energy, to emphasise the importance of a storage system, a battery in our example, to support the power generated by a PV panel. In particular, the self-sustainability of the same building with a PV plant of $90 \mathrm{~kW}$, increases from $40 \%$ to $80 \%$ if it is equipped with a $240 \mathrm{kWh}$ battery (i.e., the electrical energy that must be bought from the grid is reduced from $60 \%$ to $20 \%$, respectively). Current work of the authors is focusing on equipping the home agents with smart demandside management functionalities (e.g., to shift the usage of washing machines/dishwashing), and to quantify their effect in improving the self-sustainability of the buildings.

\section{REFERENCES}

[1] G. T. Costanzo, A. M. Kosek, G. Zhu, L. Ferrarini, M. F. Anjos, and G. Savard, "An experimental study on load-peak shaving in smart homes by means of online admission control," in Proc. of IEEE PES ISGT'12 Europe, 2012.

[2] E. Ancillotti, R. Bruno, and M. Conti, "Smoothing Peak Demands through Aggregate Control of Background Electrical Loads," in Proc. of IEEE PES ISGT'14 USA, 2014.

[3] V. Bičík, O. Holub, K. Mařík, M. Sikora, P. Stluka, and R. D’hulst, "Platform for coordination of energy generation and consumption in residential neighborhoods," in Proc. of IEEE PES ISGT'12 Europe, 2012.

[4] M. A. Al Faruque, "RAMP: Impact of rule based aggregator business model for residential microgrid of prosumers including distributed energy resources," in Proc. of IEEE PES ISGT'14, 2014.

[5] B. Asare-Bediako, P. F. Ribeiro, and W. L. Kling, "Integrated energy optimization with smart home energy management system," in Proc. of IEEE PES ISGT'12 Europe, 2012.

[6] R. Morales González, B. Asare-Bediako, J. F. G. Cobben, W. L. Kling, G. Scharrenberg, and D. Dijkstra, "Distributed energy resources for a zero-energy neighborhood," in Proc. of IEEE PES ISGT'12 Europe, 2012.

[7] R. Mortensen and K. P. Haggerty, "A stochastic computer model for heating and cooling loads," IEEE Transactions on Power Systems, vol. 3, no. 3, pp. 1213-1219, 1988.

[8] D. Callaway, "Tapping the energy storage potential in electric loads to deliver load following and regulation, with application to wind energy," Energy Conversion and Management, vol. 50, no. 5, pp. 1389-1400, 2009.

[9] M. Bozchalui, S. Hashmi, H. Hassen, C. Canizares, and K. Bhattacharya, "Optimal Operation of Residential Energy Hubs in Smart Grids," IEEE Transactions on Smart Grid, vol. 3, no. 4, pp. 1755-1766, 2012.

[10] S. Shao, M. Pipattanasomporn, and S. Rahman, "Development of Physical-Based Demand Response-Enabled Residential Load Models," IEEE Transactions on Power Systems, vol. 28, no. 2, pp. 607-614, 2013.

[11] R. Subbiah, K. Lum, A. Marathe, and M. Marathe, "Activity based energy demand modeling for residential buildings," in Proc. of IEEE PES ISGT'13, 2013, pp. 1-6.

[12] L. Paull, H. Li, and L. Chang, "A novel domestic electric water heater model for a multi-objective demand side management program," Electric Power Systems Research, vol. 80, no. 12, pp. 1446 -1451, 2010.

[13] I. Richardson, M. Thomson, and D. Infield, "A high-resolution domestic building occupancy model for energy demand simulations," Energy and Buildings, vol. 40, no. 8, pp. 1560-1566, 2008.

[14] J.-P. Zimmermann, M. Evans, J. Griggs, N. King, L. Harding, P. Roberts, and C. Evans, "Household Electricity Survey," Intertek, Tech. Rep. R66141, 2012.

[15] B. Marion, B. Kroposki, K. Emery, J. del Cueto, D. Myers, and C. Osterwald, "Validation of a Photovoltaic Module Energy Ratings Procedure at NREL," National Renewable Energy Laboratory (NREL), Tech. Rep. NREL/TP-520-26909, 1999.

[16] A. Michiorri, G. Kariniotakis, A. Bossavy, and R. Girard, "The value of schedule update frequency on distributed energy storage performance in renewable energy integration," in Proc. of IEEE PES ISGT'13 Europe, 2013.

[17] B. Zeigler, T. Kim, and H. Praehofer, Theory of Modeling and Simulation, 2nd ed. Academic Press, 2000.

[18] M. Stadler, W. Krause, M. Sonnenschein, and U. Vogel, "Modelling and evaluation of control schemes for enhancing load shift of electricity demand for cooling devices," Environmental Modelling \& Software, vol. 24, no. 2, pp. 285-295, 2009.

[19] N. Baghina, I. Lampropoulos, B. Asare-Bediako, W. Kling, and P. Ribeiro, "Predictive control of a domestic freezer for real-time demand response applications," in Proc. of the 3rd IEEE ISGT Europe, 2012, pp. 1-8. 